THF JOURNAL OF INFECTIOUS DISEASES - VOL. 134, NO. 5 - NOVEMBER 1976

(O) 1976 by the University of Chicago. All rights reserved.

\title{
Lack of Leukocyte Migration Inhibition by Hepatitis B Antigen and Normal Nonspecific Immunoreactivity in Asymptomatic Carriers
}

M. Desaules, P. C. Frei, J. Libanska, and B. Wuilleret

\author{
From the Dizision of Immunology and Allergy, Department \\ of Medicine, Centre Hospitalier Universitaire Vaudois; and \\ the Regional Blood Transfusion Center of the \\ Swiss Red Cross, Lausanne, Switzerland
}

\begin{abstract}
The immune response to hepatitis $\mathrm{B}$ surface antigen $\left(\mathbf{H B}_{\mathrm{s}} \mathrm{Ag}\right)$ was studied in 25 asymptomatic carriers by the leukocyte migration-inhibition (LMI) test in agarose. In the presence of purified $\mathrm{HB}_{\mathrm{s}} \mathrm{Ag}$, inhibition was demonstrated in only four of $\mathbf{2 5}$ carriers, in contrast to 24 of 28 patients who cleared the antigen after acute infection with hepatitis B. Tuberculin purified protein derivative (PPD) was also used as an antigen for the LMI test in these carriers. Inhibition was demonstrated in only 12 of 25 individuals who had positive PPD skin tests, in contrast to all of 14 normal noncarrier individuals with positive PPD skin tests and none of 12 normal noncarrier individuals with negative PPD skin tests. A nonspecific immunological investigation of the asymptomatic carriers gave normal results. The lack of an immune response to $\mathrm{HB}_{\mathrm{g}} \mathrm{Ag}$ was thought to be responsible for the persistence of the antigen and also for the absence of symptoms.
\end{abstract}

About $0.2 \%$ of the blood donors in this part of Europe are carriers of hepatitis B surface antigen $\left(\mathrm{HB}_{\mathrm{s}} \mathrm{Ag}\right)$. Some of these asymptomatic carriers have slightly elevated levels of transaminases, whereas others do not exhibit any biochemical sign of hepatic cytolysis but have slight histological abnormalities of the liver. A third group of these carriers are normal, both biochemically and histologically [1-3].

Since $\mathrm{HB}_{\mathrm{s}} \mathrm{Ag}$ is usually associated with acute hepatitis and disappears at the time of recovery, it is difficult to explain how the antigen can persist in the third (normal) group of carriers without damaging the liver. The fact that $\mathrm{HB}_{\mathbf{s}} \mathrm{Ag}$ can persist in two conditions as different as the healthy carrier state and chronic hepatitis is also problematical.

Received for publication February 6, 1976, and in revised form May 11, 1976.

We thank Dr. P. Kocher, Centre de Transfusion Sanguine, La Chaux-de-Fonds, for allowing us to study four of his blood donors.

This work was performed with the financial support of the Centre de Recherche sur les Lymphomes Malins, Lausanne, Switzerland.

A portion of this study was presented at the European Society for Clinical Investigation, Rotterdam, Netherlands, April 25-27, 1974.

Please address requests for reprints to Dr. P. C. Frei, Division of Immunology and Allergy, Department of Medicine, Centre Hospitalier Universitaire Vaudois, Lausanne CH 1011, Switzerland.
The immune state of symptomatic and asymptomatic carriers has been thought to be responsible for the persistence of the antigen. The nonspecific cellular immune response was found to be impaired by some authors [4-6] and normal by others $[1,7,8]$. The specific immune response to $\mathrm{HB}_{\mathrm{s}} \mathrm{Ag}$ has also been studied in vitro in blood from a limited number of carriers. No inhibition of leukocyte migration in the presence of $\mathrm{HB}_{\mathrm{s}} \mathrm{Ag}$ was found by Yeung Laiwah et al. [9] or by Dudley et al. [10], and inhibition was found only infrequently by Vittal et al. [11]. However, Lee et al. [12] observed inhibition in 10 of 37 $\mathrm{HB}_{\mathrm{s}} \mathrm{Ag}$-positive blood donors. Irwin et al. found no migration-inhibition factor (MIF) activity in five carriers tested by an indirect method [13]. Koszikowski et al. [14] did not find any stimulation of lymphocytes by $\mathbf{H B}_{\mathbf{8}} \mathrm{Ag}$ in 10 carriers, and also found none in 10 patients who had recovered from hepatitis $\mathbf{B}$ infection without producing detectable levels of antibody.

The leukocyte migration-inhibition (LMI) test in agarose allowed us to use only very small amounts of purified $\mathrm{HB}_{\mathrm{B}} \mathrm{Ag}$. With this technique, we have shown [15] the constant appearance of a specific inhibition of leukocyte migration by $\mathrm{HB}_{\mathrm{s}} \mathrm{Ag}$ after recovery from acute infection with hepatitis B. This inhibition was observed in almost all patients who cleared the antigen, whereas the antibody became demonstrable by radioim- 
munoassay in only half of the patients. The absence of migration inhibition during and immediately after the acute phase of the disease was attributed to nonspecific anergy, since migration inhibition by purified protein derivative (PPD) disappeared temporarily at that time [16].

From these findings it was hypothesized that specific cell-mediated immunity might be responsible for the clearance of $\mathrm{HB}_{\mathrm{g}} \mathrm{Ag}$. The present study extends this investigation to asymptomatic carriers. The results demonstrate the absence of migration inhibition by $\mathrm{HB}_{\mathrm{s}} \mathrm{Ag}$ in all but four of 25 asymptomatic carriers of $\mathrm{HB}_{\mathrm{B}} \mathrm{Ag}$.

\section{Materials and Methods}

Selection of donors. $\mathrm{HB}_{\mathrm{g}}$ Ag-positive blood donors were subjected to careful taking of their medical history, physical examination, and blood tests, including levels of aspartate aminotransferase (SGOT) and alanine aminotransferase (SGPT), prothrombin, alkaline phosphatase, bilirubin, protein, and electrophoresis. Only those donors who proved to be normal according to these criteria and who had no history of hepatitis were selected for study. This group was reexamined in the same manner nine to 12 months later to establish the persistence of $\mathrm{HB}_{\mathrm{s}} \mathrm{Ag}$ in the blood and the absence of any symptoms. The possibility of a donor incubating acute hepatitis could thus be avoided. No liver biopsy was performed because of the absence of indication in these asymptomatic donors. Titers of $\mathrm{HB}_{\mathbf{a}} \mathrm{Ag}$ were measured by counterimmunoelectrophoresis. In two carriers, $\mathrm{HB}_{\mathrm{s}} \mathrm{Ag}$ was detectable by radioimmunoassay only. Twenty-five individuals (18 males and seven females), aged 21-63, were finally selected for the study.

Nonspecific immune state. The three main immunoglobulins were measured by radial immunodiffusion (Tripartigen Behringwerke, Marburg, Germany). Humoral response was tested by titration of isoagglutinin, antistreptolysin (Streptolysin Istituto Sierterapico Milanese, MiIan, Italy), and antistaphylolysin (Staphylolysin Behringwerke, Marburg, Germany). Delayed-type skin reactivity was investigated by skin-testing with a standard group of five antigens: tuberculin PPD (5 units; Statens Seruminstitut, Copenhagen, Denmark), streptokinase-streptodorn- ase (250 units/ml; Varidase; Lederle, Pearl River, N.Y.), candidine (Bencard; Beecham, Brentford, Middlesex, England), trichophytine (Beecham), and mumps skin-test antigen (Eli Lilly and Company, Indianapolis, Ind.).

Purification of $H B_{s} \mathrm{Ag}$. Sera with a titer of $\mathrm{HB}_{\mathrm{s}} \mathrm{Ag}$ of $>1: 256$ by counterimmunoelectrophoresis were pooled. $\mathrm{HB}_{6} \mathrm{Ag}$ was precipitated by polyethylene glycol 6,000; the precipitate was redissolved in distilled water, dialyzed against 0.05 M sodium barbital buffer ( $\mathrm{pH}$ 8.6), and further purified by agarose-block electrophoresis in the same buffer. The $\mathrm{HB}_{\mathrm{s}}$ Ag-rich fractions were pooled and concentrated by vacuum dialysis against phosphate buffer. The $\mathrm{HB}_{\mathrm{B}} \mathrm{Ag}$ was then separated from trace amounts of contaminating proteins by ultracentrifugation on a $10 \%-30 \%$ $(\mathrm{wt} / \mathrm{wt})$ sucrose gradient. The preparation was sterilized by filtration through Millex microfilters (pore size, $45 \mu \mathrm{m}$; Millipore Corp., Bedford, Mass.) and finally was concentrated by vacuum dialysis (membrane filter SM 132000; Sartorius, Göttingen, Germany) against medium TC 199 (Difco, Detroit, Mich.), until a titer of 1:16 by counterimmunoelectrophoresis was reached. No precipitation line was found in agar double-diffusion with antisera to whole human serum. The $\mathrm{HB}_{8} \mathrm{Ag}$ preparation was used undiluted in the LMI test.

LMI test. This test was performed under agarose according to the method of Clausen [17]. Details of this method as performed with $\mathrm{HB}$, $\mathrm{Ag}$ in our laboratory have been described [18]. In brief, $2.5 \times 10^{7}$ leukocytes, containing at least $75 \%$ polymorphonuclear leukocytes, were suspended in $0.1 \mathrm{ml}$ of the antigen preparation. The suspension was incubated for $30 \mathrm{~min}$ at $37 \mathrm{C}$ in an atmosphere of $2.5 \% \mathrm{CO}_{2}$, and $5 \mu \mathrm{l}$ were introduced into each of eight wells punched in an agarose layer. After incubation for $18 \mathrm{hr}$, the areas of migration were measured by planimetry. The mean surface area of the eight wells was expressed as the percentage of the migration in a control preparation without antigen. Values of $<90 \%$ were considered to indicate inhibition. Leukocytes from each individual were tested in the presence of two antigens, purified $\mathrm{HB}_{\mathrm{s}} \mathrm{Ag}$ and tuberculin PPD $(25 \mu \mathrm{g} / \mathrm{ml})$, without preservative. The statistical evaluation was made according to Student's $t$-test for unpaired values. 
Results

The titers of circulating $\mathrm{HB}_{\mathrm{8}} \mathrm{Ag}$ ranged from 1: 1,024 to $1: 1$ by counterimmunoelectrophoresis, and, in two cases, antigen was detectable only by radioimmunoassay (Ausria II; Abbott Laboratories, North Chicago, Ill.). The titer was strikingly stable during the observation period and never varied by more than one dilution step. Tests of hepatic function were normal in all of the individuals selected for study. On retesting a few months later, the antigen was still present and the results of hepatic function tests were normal. The mean area of leukocyte migration in the presence of $\mathrm{HB}_{\mathrm{s}} \mathrm{Ag}$ was $101.9 \%$ of that in the control without antigen (SE \pm 3.2 ). Thus, no immune response to $\mathrm{HB}_{\mathrm{s}} \mathrm{Ag}$ could be demonstrated in these carriers. Only in cases no. 1, 5, 16, and 23 were individual values of $<90 \%$ demonstrable.

Figure 1 clearly shows the lack of leukocyte inhibition by $\mathrm{HB}_{\mathrm{s}} \mathrm{Ag}$ in asymptomatic carriers, compared with individuals who cleared the antigen after acute infection with hepatitis $B$. The difference is significant $(t=5.35 ; P<0.001)$. Leukocytes from carriers did not behave differently from those from normal individuals $(t=$ $0.34 ; 0.3<P<0.4$ ) or from those from patients with acute hepatitis $B$ infection $(t=0.32 ; 0.3<$ $P<0.4)$ in the presence of $\mathrm{HB}_{\mathrm{g}} \mathrm{Ag}$.

Inhibition of leukocyte migration in the pres- ence of PPD (figure 2) was demonstrable in 12 carriers only, although all 25 carriers had a positive skin test with PPD. In normal individuals, however, the LMI test in agarose gave a good correlation with the PPD skin-tests, as shown in figure 2. The mean area of migration in the presence of PPD was $71.0 \%$ ( $\mathrm{SE} \pm 2.3$ ) in PPD-positive normal individuals, $95.7 \%(\mathrm{SE} \pm 4.4)$ in PPD-positive patients with acute hepatitis B infection, and 91.8\% (SE \pm 3.2 ) in PPD-positive carriers. Thus, the leukocytes from these asymptomatic carriers behaved, in the presence of PPD, not like those from normal individuals $(t=$ 4.55; $P<0.001)$, but in the same manner as those from acutely infected patients $(t=0.73$; $0.2<P<0.25$ ). The reproducibility of the LMI test under agarose was satisfactory, as judged by the eight simultaneous measurements in each case; in the four cases with inhibition, all eight values were $<90 \%$. The stimulation observed in a few cases may be without significance or may be interpreted as a weak sensitization [18].

Results of nonspecific immunological screening were normal. Values obtained for the humoral parameters were normal, except for a few isolated titers of antibody. This exception can also occur in normal individuals. Only one case had low values for all three antibodies tested (two dilution steps below the lowest limit) and for IgG $(550 \mathrm{mg} / 100 \mathrm{ml})$. The delayed hypersensitivity, as judged by the skin tests, was normal in all patients.
Figure 1. Migration, in the presence of purified hepatitis $B$ surface antigen $\left(\mathrm{HB}_{\mathrm{S}} \mathrm{Ag}\right)$, of leukocytes from normal individuals (left), patients during and after acute hepatitis $B$ infection (center), and asymptomatic carriers of $\mathrm{HB}_{\mathrm{s}} \mathrm{Ag}$ (right). Points represent the surface of migration expressed as the percentage of the migration in a control preparation without antigen. The short horizontal lines are means \pm SD. Broken line represents $100 \%$ migration.

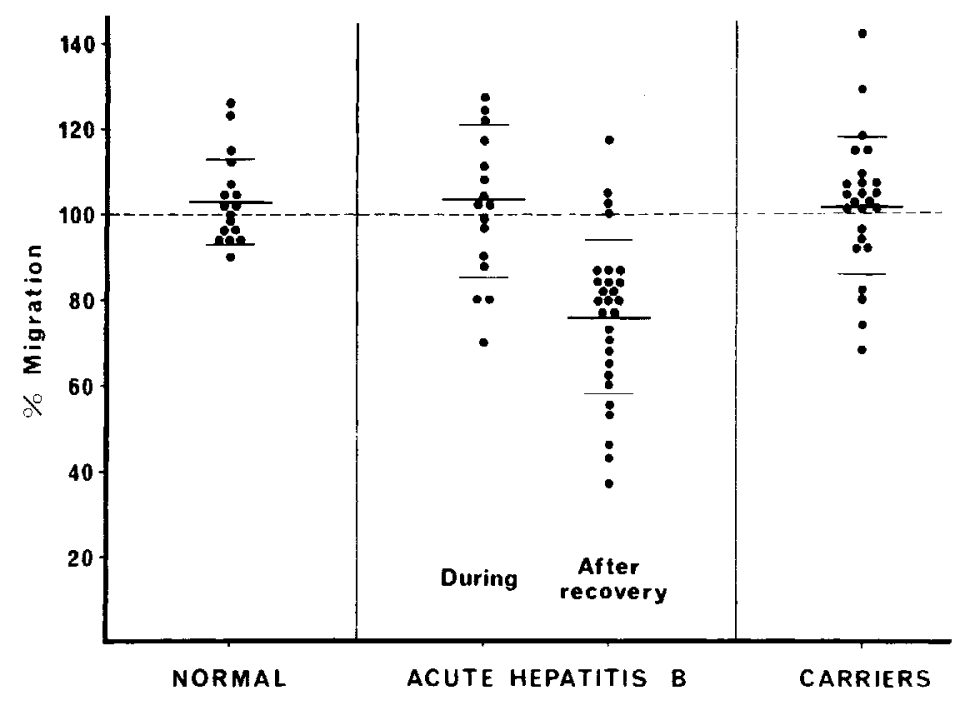




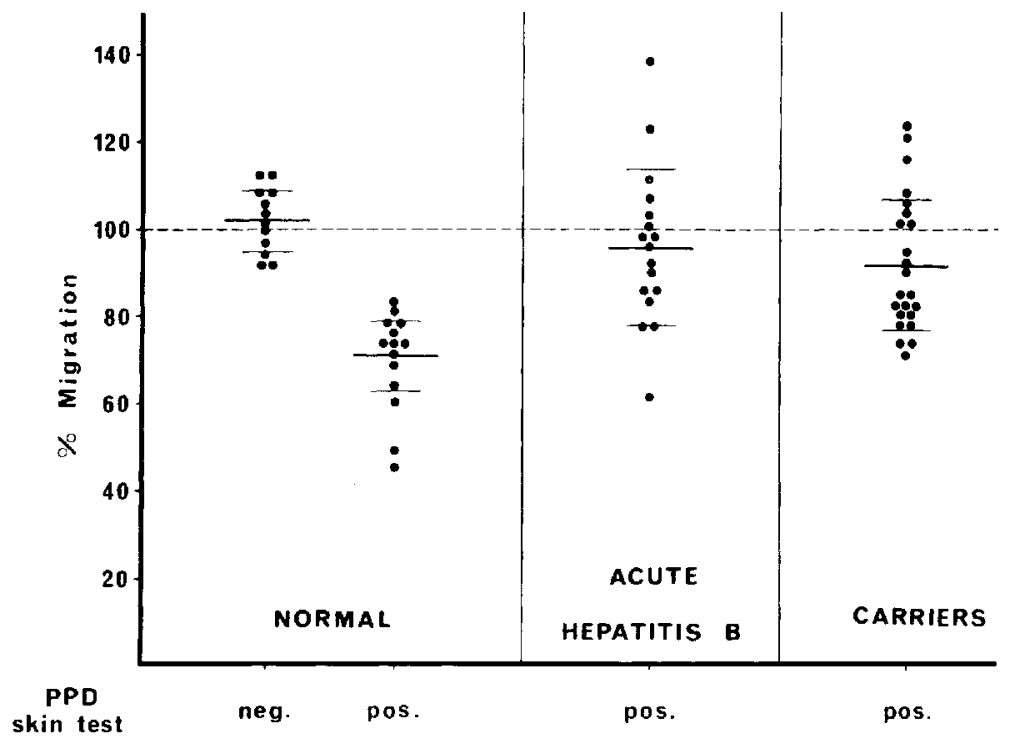

Figure 2. Migration, in the presence of purified protein derivative (PPD), of leukocytes from normal PPDnegative individuals and normal PPD-positive individuals (left), PPDpositive individuals during acute hepatitis B infection (center), and PPD-positive asymptomatic carriers of hepatitis B surface antigen (right). The short horizontal lines are means \pm So. Broken line represents $100 \%$ migration.

\section{Discussion}

The inhibition of leukocyte migration by $\mathrm{HB}_{\mathrm{s}}$ $\mathrm{Ag}$ in carriers occurred infrequently (four of 25 carriers). This finding contrasts with the nearly constant inhibition we observed in patients who cleared $\mathrm{HB}_{\mathrm{B}} \mathrm{Ag}$ (24 of 28 patients). Consequently, we believe that the specific immune response demonstrated by the LMI test is probably responsible for elimination of the antigen, which occurs during recovery from hepatitis B infection, and that the lack of this response may explain the carrier state.

Nearly all authors consider the LMI test as an index of cell-mediated immunity. Although this hypothesis has not been proven, the following findings encourage us to support it for the moment. In our experiments with $\mathrm{HB}_{\mathrm{6}} \mathrm{Ag}$ as an antigen, migration inhibition did not correlate with antibody production $[15,18]$. In our experiments with PPD, the correlation with the results of delayed skin tests was excellent (figure 2). Furthermore, Lambert et al. ${ }^{1}$ and Trepo et al. [19] found no relation between the presence of $\mathrm{HB}_{\mathrm{g}}$ Ag-anti- $\mathrm{HB}_{8} \mathrm{Ag}$ complexes and any of the conditions studied here.

1 P. H. Lambert, E. Tribollet, A. Celada, K. Madalinski, P. C. Frei, P. A. Miescher, "Circulating Immune Complexes Involving $\mathrm{HB}_{\mathrm{s}} \mathrm{Ag}$ in Patients with Acute and Chronic Hepatitis in Healthy Carriers and in Polyarteritis Nodosa," manuscript in preparation.
Our observations also contribute to explanations of the absence of lesions in the carriers. The lesions of hepatitis cannot, of course, be produced by the virus itself. They might be the consequence of the immune response demonstrated by the LMI test, and the lack of this response in carriers would explain the absence of cytolysis in the liver. One must then consider the reason that this response could not be demonstrated during the acute phase of hepatitis (figure 1), when the liver is most severely attacked. This lack of response is probably related to a broad, nonspecific anergy during the acute phase. We have shown $[16,18]$ that the migration of leukocytes from PPD-positive individuals was not inhibited by PPD during hepatitis. Experiments with PPD as antigen (figure 2) also showed that leukocytes from some carriers behaved like those from patients with acute hepatitis $\mathbf{B}$ infection; the mean surface areas of migration were $91.8 \%$ and $95.7 \%$, respectively, without significant difference between the two values. The anergy demonstrable in vitro during the acute disease exists, to a lesser extent, in healthy carriers. Thus, it seems that the circulating agent can itself produce a nonspecific anergy, even in the absence of tissue damage. Note that the anergy in these two conditions was not demonstrable by the skin tests. These tests may be more sensitive than the LMI test or may show a slightly different type of response. 
The impairment of the immune response demonstrable by the LMI test in carriers seems to be an isolated defect, since the results of the nonspecific immunological investigation were indistinguishable from those one would obtain in normal individuals. Only one carrier had low titers of antibody and a low IgG level. In this respect, our results differ from those of others [4-6]. This difference is probably related to our stricter criteria of selection, which excluded individuals with biological signs of hepatic disease.

\section{References}

1. Bolin, T. D., Davis, A. E., Liddelow, A. G. Liver disease and cell-mediated immunity in hepatitis-associated antigen (HAA) carriers. Gut 14:365-368, 1973.

2. Reinicke, V., Dybkjaer, E., Poulsen, H., Banke, O., Lylloff, K., Nordenfelt, E. A study of Australia-antigenpositive blood donors and their recipients with special reference to liver histology. N. Eng1. J. Med. 286: $867-870,1972$.

3. Griffin, F., Jr. Hepatitis B antigenemia in apparently healthy blood donors. J.A.M.A. 226:753-755, 1973.

4. Giustino, V,, Dudley, F. J, Sherlock, S. Thymus-dependent lymphocyte function in patients with hepatitisassociated antigen. Lancet 2:850-853, 1972

5. Halikowski, B., Korczowski, R., Zajaczkowski, J. Odczyn skorny na dwunitrochlorobenzen (DNCB) u nosicieli antygenu Australia. Pediatr. Pol. 47:1071-1075, 1972.

6. Ortona, L., Pizzigallo, E., Federico, G., Laghi, V. Richerche sui donatori di sangue au positivi: stimolazione in vitro dei linfociti con PHA. Ann. Sclavo 13:35-48, 1971.

7. Nielsen, J. O., Reinicke, V., Dietrichson, O., Andersen, V., Thornsen, M., Andersen, E. Immunological studies of Australia antigen carriers with and without liver diseases. Clin. Exp. Immunol. 15:9-16, 1973.

8. Sutnick, A. I., Bugbee, S. J., London, W. T., Loeb, L. A., Peyretti, F., Litwin, S., Blumberg, B. S. Lymphocyte function in normal people with persistent Australia antigen. J. Lab. Clin. Med. 82:79-85, 1973.

9. Yeung Laiwah, A. A. C., Chaudhuri, A. K. R., Anderson, J. R. Lymphocyte transformation and leuco- cyte migration inhibition by Australia antigen. Clin. Exp. Immunol. 15:17-34, 1973.

10. Dudley, F. J., Giustino, V., Sherlock, S. Cell-mediated immunity in patients positive for hepatitis-associated antigen. Br. Med. J. 4:754-756, 1972.

11. Vittal, S. B. V., Dourdourekas, D., Shobassy, N., Gerber, M., Telischi, M., Szanto, P. B., Steigmann, F., Clowdus, B. F. Asymptomatic hepatic disease in blood donors with hepatitis B antigenemia. Am. J. Clin. Pathol. 62:649-654, 1974.

12. Lee, W. M., Reed, W. D., Mitchell, C. J., Eddleston, A. L. W. F., Dymock, I., Williams, R. Cell-mediated immunity to hepatitis $B$ antigen in blood donors with persistent antigenaemia or high titer antibody. Digestion 10:362, 1974.

13. Irwin, G. R., Jr., Hierholzer, W. J., Jr., Cimis, R., McCollum, R. W. Delayed hypersensitivity in hepatitis B: clinical correlates of in vitro production of migration inhibition factor. J. Infect. Dis. 130:580-587, 1974.

14. Koszinowski, U., Thomssen, R., Schober, A. In-vitroStimulation der Lymphozyten von HB-AntikörperTrägern durch HB-Antigen (Australia-Antigen). Dtsch. Med. Wochenschr. 98:262-267, 1973.

15. Frei, P. C., Erard, Ph., Zinkernagel, R. Cell-mediated immunity to hepatitis-associated antigen (HAA) demonstrated by leukocyte migration test during and after acute hepatitis B. Biomedicine [Express] 19: 379-383, 1973.

16. Erard, P., Frei, P. C., Peitrequin, R., Hofstetter, J.-R., Magnenat, P. Etude de l'immunité cellulaire spécifique de l'antigène Australia. Résultats préliminaires dans différentes formes d'hépatite B. Schweiz. Med. Wochenschr. 104:1882-1885, 1974.

17. Clausen, J. E. Tuberculin-induced migration inhibition of human peripheral lymphocytes in agarose medium. Acta Allergol. (Kbh.) 26:56-80, 1971.

18. Erard, P. Technical study of the leukocyte migration inhibition test in agarose. Application to PPD and to hepatitis B antigen. Clin. Exp. Immunol. 18:439448, 1974.

19. Trepo, C. G., Zuckerman, A. J., Bird, R. C., Prince, A. M. The role of circulating hepatitis $B$ antigen/antibody immunc complexes in the pathogenesis of vascular and hepatic manifestations in polyarteritis nodosa. J. Clin. Pathol. 27:863-868, 1974. 